\title{
Possibilidades de aprendizagem: reflexões sobre neurociência do aprendizado, motricidade e dificuldades de aprendizagem em cálculo em escolares entre sete e 12 anos
}

\section{Possibilities for learning: reflections on the neuroscience of learning, and motor and learning disabilities in calculating among 7 to 12 year old students}

\author{
Cleonice Terezinha Fernandes ${ }^{1}$. Cristiano Alberto Muniz ${ }^{2}$. \\ Maria Isabel Mourão-Carvalhal ${ }^{3}$. Paulo Moreira Silva Dantas ${ }^{4}$
}

\begin{abstract}
Resumo: $\mathrm{O}$ avanço das neurociências na educação aborda aspectos da memória, da aprendizagem e da indissociável relação corpo-mente para aprendizagem do sujeito. Este estudo buscou correlacionar tais conceitos às Dificuldades de Aprendizagem (DA) específicas em cálculo (aritmética) e pressupostos da Educação Matemática. O objetivo foi investigar o impacto de um programa pedagógico, com atividades didático-manipulativas usando corpo/movimento, em um estudo longitudinal com 37 escolares com indicativos de DA em cálculo, entre 7 e 12 anos, oriundos de um colégio privado em Cuiabá, MT. Como resultado, houve um aumento no desempenho escolar da amostra, mostrando que o uso do corpo e de atividades somatossensoriais podem auxiliar alunos com DA a focarem a atenção e melhorar sua autonomia acadêmica, senso de autoeficácia e compreensão matemática. A indissociabilidade corpo-mente e a realização bem-sucedida do presente estudo confirmam a necessidade de se promoverem pesquisas em experiências e aprendizagem motoras para minimizar impactos das DA.
\end{abstract}

Palavras-chave: Neurociência. Desempenho psicomotor. Aritmética. Cognição numérica. Educação matemática.

Abstract: The advancement of neurosciences in education presents aspects of memory, learning and the inseparability of the body-mind relationship in the learning of students. This study sought to correlate these concepts with Learning Disabilities (LD) specifically in arithmetic and principles of Mathematics Education. The purpose was to investigate the impact of an educational program with didactic and manipulative activities using movement-body in an experimental typology study with 37 students (of a private college in Cuiabá, MT, Brazil) between 7 and 12 years old with indicative of LD in calculus. The main result was the increase of the academic results of the students, showing that the use of the body and somatosensory activities can help students with LD to focus attention and improve their academic autonomy, sense of self-efficacy and mathematical understanding. Believing in the inseparability of the body-mind relationship and in the positive outcome of this study we conclude the need to promote research in motor learning to minimize impacts of $\mathrm{LD}$.

Keywords: Neuroscience. Psychomotor performance. Arithmetic. Numerical cognition. Mathematics education.

\footnotetext{
${ }^{1}$ Faculdade de Biologia, Universidade de Cuiabá (UNIC), Avenida Beira Rio, 3100, Jardim Europa, CEP 78015480, Cuiabá, MT, Brasil. E-mail: <cleo_terezinha@hotmail.com>

${ }^{2}$ Departamento de Métodos e Técnicas, Faculdade de Educação, Universidade de Brasília (UnB), Brasília, DF, Brasil.

${ }^{3}$ Universidade Trás-os-Montes e Alto Douro, Vila Real, Portugal.

${ }^{4}$ Departamento de Educação Física, Universidade Federal do Rio Grande do Norte, Natal, RN, Brasil.
} 


\section{Introdução}

$\mathrm{Na}$ atualidade, o avanço dos estudos nas neurociências alcança a área da educação neurociência do aprendizado ou neuroeducação. Importantes autores, como Damásio (1996), Yzquierdo (2010) e Herculano-Houzel (2009), falam de aspectos da memória, da aprendizagem e da indissociável relação corpo-mente para o desenvolvimento e aprendizagem do sujeito.

Segundo Yzquierdo (2010), exemplos dessas atuais revoluções são os mecanismos de formação da memória (neurochips) e exames de Ressonância Magnética Funcional (fMRI), ou neuroimagem, técnica não invasiva que permite monitorar o cérebro em funcionamento e observar as diferentes áreas cerebrais que se ativam na execução de tarefas cognitivas.

Tais avanços motivaram a presente investigação, cujo referencial teórico centra-se nos conceitos atuais de Dificuldades de Aprendizagem (DA), a formação de conceitos matemáticos em crianças, articulados sob a perspectiva da referida neurociência do aprendizado, especificamente em neurobiologia, em suas bases neurais do conhecimento e cognição numérica.

O objetivo do presente artigo será discutir a dimensão pedagógica e qualitativa de um programa de intervenção desenvolvido por meio de atividades centradas no corpo/movimento e seus respectivos pressupostos matemáticos, num estudo longitudinal com 37 escolares entre 7 a 12 anos, com indicativos de DA em cálculo - contagem, quantificação e resolução de situações-problema.

\section{Bases neurais do conhecimento}

A concepção de aprendizagem deste estudo está ancorada no conceito atual da neurobiologia, que é, em resumo, o estudo da organização dos circuitos funcionais das células nervosas, que processam a informação e medeiam o comportamento. Muito se tem avançado nestas pesquisas, dadas as crescentes inovações dos já referidos estudos de ressonância magnética funcional, que permitem estudar o cérebro em atividade. Herculano-Houzel (2009), bióloga e neurocientista brasileira, denomina esta área como neurociência do aprendizado. Para Damásio (1996), o centro da neurobiologia seria o processo por meio do qual as representações neurais se transformam em imagens nas nossas mentes, o que cada sujeito experiencia de modo particular - conceito que será desenvolvido a seguir.

Damásio (1996) faz interessante distinção conceitual entre corpo, cérebro e mente. Para ele, o organismo é o resultado da interação entre corpo e cérebro em duas vias de interconexão: pela via dos nervos motores e sensoriais periféricos, e pela via mais antiga em termos evolutivos, a corrente sanguínea, que transporta sinais químicos - hormônios, neurotransmissores e neuromoduladores.

O citado autor destaca o papel do neurotransmissor serotonina no aprendizado e a sua contribuição no comportamento social, visto que a presença ou ausência dessa substância em sistemas (cerebrais) específicos - cujos receptores são também específicos - modificam o funcionamento desses sistemas; tal modificação altera, por cadeia, os outros sistemas - a expressão final da mudança é comportamental e cognitiva.

Outros neurotransmissores-chave são a dopamina, a norepinefrina e a acetilcolina; todos eles são liberados por neurônios localizados em pequenos núcleos do tronco cerebral 
ou do procencéfalo basal, cujos axônios terminam no neocórtex, nos componentes corticais e subcorticais do sistema límbico. [responsável pelas emoções] [...] nos gânglios basais e no tálamo. Um dos efeitos da serotonina nos primatas consiste na inibição do comportamento agressivo todavia curiosamente desempenha outros papéis em outras espécies. (DAMÁSIO, 1996, p. 102)

Entretanto, Damásio (1996) alerta para a sensacionalização que esse assunto tem causado. Para ele, são necessários estudos mais profundos, que levem em conta os aspectos sociais e neuroquímicos para afirmar que a serotonina diminuiria, por exemplo, índices de violência. Segundo o autor, os fatores socioculturais passados e presentes têm uma participação poderosa no processo.

Nesta interação entre corpo e cérebro dos organismos complexos, surgem as respostas ao ambiente, porém tais organismos complexos, como o humano, fazem mais do que interagir, gerar respostas espontâneas ou reativas, conhecidas como comportamento: eles armazenam imagens a partir desta conexão com a realidade.

Esse é outro conceito que buscamos trabalhar neste artigo, o das respostas internas dos organismos, algumas das quais constituem imagens - sonoras, visuais, olfativas, somatossensoriais - que são a base da mente, considerando que "mente é [...] possuir a capacidade de exibir imagens internamente e de ordenar essas imagens com um processo chamado pensamento" (DAMÁSIO, 1996, p. 116).

Conforme mencionado anteriormente, para Damásio (1996), o cerne da neurobiologia é o processo por meio do qual as representações neurais se transformam em imagens nas mentes dos sujeitos que as experienciam de modo exclusivo, ou seja, cada um compreende-as à sua maneira particular. Assim, a natureza das imagens de algo que ainda não aconteceu - e que pode, de fato, nunca vir a acontecer - não é diferente da natureza das imagens acerca de algo que já aconteceu e que retemos. Tanto as imagens perceptivas (do presente momento) quanto aquelas evocadas do passado ou de planos para o futuro são construções do cérebro.

Um conceito interessante que deriva destas reflexões é o fato de que pensar nada mais é do que possuir capacidade de exibir (evocar) imagens internamente. Podemos traduzir pensar de maneira mais formal pela expressão possuir fenômenos mentais - cognição ou processos cognitivos. "Alguns organismos possuem tanto comportamento como cognição. Outros desenvolvem ações inteligentes, mas não possuem mente. Nenhum organismo parece ter mente e não ter ações" (DAMÁSIO, 1996, p. 116).

A aprendizagem, portanto, do ponto de vista biofisiológico, está associada a prazer, liberação de serotonina - neurotransmissor, memória (YZQUIERDO, 2010), atenção voluntária focada e significação do que se está aprendendo. A formação do pensamento (evocação das imagens "armazenadas") tem relação estreita com as circunstâncias em que elas - as imagens - foram produzidas. E, neste aspecto, a linguagem também tem um papel fundamental na evocação das imagens e, portanto, na formação desta mente socialmente partilhada (VIGOTSKY, 1991). Para a neurobiologia, quanto mais recursos forem empregados na transmissão de uma informação, tanto melhor ela se fixará na memória de longa duração (HERCULANO-HOUZEL, 2009), o que tem importantes implicações pedagógicas para a estimulação da aprendizagem dentro e fora da escola.

Nesse sentido, Damásio (1996) apresenta o conceito de conhecimento visceral - a percepção do sujeito entre a relação objeto versus estado emocional do seu corpo. Acerca disso, Yzquierdo (2010) acredita que os seres humanos não chegaram nem perto do limite cerebral 
para armazenar informações, provavelmente por não o exercitarem suficientemente ou pela interferência das emoções.

Na perspectiva dessa reflexão neurobiológica, este estudo está centrado nas significativas evidências da conexão corpo (organismo) e mente (imagens) para construção do aprendizado.

\section{Neurociência do aprendizado matemático}

Rato e Caldas (2010a) referenciam que crianças menores de 3 anos demonstram sentido de cardinalidade. Kaufmann e Dowker (2009) acreditam, também, que as habilidades de processar quantidades e realizar cálculos simples ocorrem antes da escolarização. Estes últimos compilaram estudos desde final de 1990, os quais sugerem que, mesmo crianças pré-verbais, são capazes de discriminar quantidades numéricas e fazer ordenação quando estimuladas.

Dehaene (1997) aponta nesta mesma direção ao afirmar que bebês são capazes de realizar operações aritméticas com quantidades perceptíveis, em experiências similares a utilizadas com animais. Trata-se de um reconhecimento perceptivo de quantidades elementares até 5 (cinco). Piaget (1999) não encontrou esta habilidade nos bebês, justamente por usar exclusivamente a linguagem, segundo Muniz (1999). Por essa razão, as investigações piagetianas são vistas, atualmente, como portadoras de alguns equívocos metodológicos e linguísticos.

Ao término do primeiro ano de vida, os bebês estariam com um significativo repertório rudimentar de aritmética, conquistado por maturação cerebral simples ou por aprendizagem, diferentemente dos outros animais - chipanzés, por exemplo, precisam repetir centenas de vezes a mesma lição para reterem apenas fragmentos dela (DEHAENE, 1997).

Embora os humanos partam de uma capacidade occipito-parietal, derivada do sistema visual localizador espacial, também comum em outros animais, o primeiro feito que nos distingue destes na capacidade matemática é a criação de símbolos que deixam o cérebro livre para operar com as abstrações do mundo real (DEHAENE, 1997); abstração esta conquistada pelas crianças somente mais tarde, e completamente dependente de experiências estimuladoras e maturação cerebral simples (MUNIZ, 1999). Vale lembrar que o material genético humano é 98\% idêntico ao de um chimpanzé (DEHAENE, 1997).

Rato e Caldas (2010a) acreditam que ainda são incipientes as pesquisas em termos de mapeamento das competências lógico-matemáticas, devido à complexidade das múltiplas interações funcionais do cérebro; e citam estudos nos quais parece difícil a localização de uma região específica para o raciocínio matemático. Este desconhecimento é agravado pelo reduzido número de pesquisas na área (KAUFMANN; DOWKER, 2009; RATO; CALDAS, 2010a).

Todavia, Dehaene et al. (2004) indicaram que o sentido do número depende, essencialmente, das áreas parietal e pré-frontal com o segmento horizontal do sulco bilateral intraparietal.

\section{A cognição numérica}

Nos estudos de Dehaene (1997), encontra-se o córtex frontal na aquisição do conceito de número, também reconhecido como córtex-motor - controle dos movimentos. Para Dehaene (1997), manipular quantidades numéricas mentalmente envolve circuitos neurais da região parietal inferior de forma vital e específica. Na região parietal, há um circuito dedicado à representação contínua da informação dos objetos que se veem no espaço. 
Muito embora Dehaene (1997), ao considerar a construção fundamental do conhecimento matemático - que inclui resolução de situações-problema, gerar ações de interpretação cognitiva, planejamento, experimentação, correção -, conclui que ele ativa instantaneamente várias redes neurais - regiões do cérebro, e não apenas algumas áreas definidas.

Para Dehaene (1997), toda matematização requer uma rede neuronal extensa. O cérebro se comporta como uma rede de agentes limitados incapazes de realizar feitos isoladamente, mas, na divisão de trabalho, podem resolver problemas complexos. Segue afirmando que, mesmo a multiplicação simples de dois números, requer a colaboração de dezenas de milhões de células nervosas, distribuídas em várias áreas do cérebro (DEHAENE, 1997).

Núñez (2011) contrapõe-se à ideia de que a cognição numérica seria inata para os seres humanos, mediante resultados arqueológicos e históricos. Para ele, a região mental numérica (mental number line, MNL) não seria inata, cuja localização específica é bilateral, existente nos sulcos intraparietais do cérebro humano. A cognição numérica seria cultural e historicamente mediada por mecanismos cognitivos, como mapas conceituais e representações externas adquiridas pela educação e cultura. Núñez (2011) crê que a cognição numérica permitiria múltiplos arranjos com grande influência do meio, da cultura e das experiências do sujeito, com o que concorda Dehaene (1997).

Nesta mesma direção, Dehaene (1997) também acredita que o conhecimento matemático não é inato, devido a estudos sobre nosso material genético e sistema neurológico, pouco alterado em milhares de anos. Para ele, a diferença crucial é de que o desenvolvimento de nossa capacidade cognitiva - articulação entre neurônios - é cada vez mais explorado, o que explicaria os atuais avanços nas capacidades humanas em matemática. Segundo o autor, as nossas mais elaboradas abstrações matemáticas são o resultado da combinação entre um acabamento requintado de nosso cérebro - ancestral comum a alguns outros mamíferos - e milhões de anos de seleção de ferramentas matemáticas (DEHAENE, 1997).

Kovas et al. (2007) fizeram um estudo para compreender a influência de causas genéticas e ambientais em desempenhos matemáticos, com 5.348 crianças de 10 anos de idade, no Reino Unido, em pares do mesmo sexo e gêmeos. O resultado foi nenhuma diferença entre os sexos, tanto nas habilidades quanto nas incapacidades matemáticas; o desempenho baixo foi dado, igualmente, por fatores genéticos e ambientais.

\section{Dificuldades de Aprendizagem (DA) e DA em Cálculo}

Ainda não é conhecida uma etiologia exata para as DA, o que, para Fonseca (2004), justifica-se por tratar-se de um campo de estudo ainda conceitualmente pouco definido, muito embora a literatura internacional traga um significativo percentual de $5 \%$ de incidência de DA dentre os escolares (SMITH; STRICK, 2001).

Para efeito de caracterizar a população com DA, Fonseca (2004) aponta quatro importantes parâmetros: (1) adequada oportunidade de aprendizagem; (2) discrepância entre potencial de aprendizagem e os resultados escolares; (3) disfunção no processo de informação ao apresentar desordens básicas na aprendizagem, apresentando ou não uma disfunção do sistema nervoso central (SNC); e (4) fatores de exclusão, como: privações associadas aos aspectos socioeconômicos, sinais de deficiência intelectual-mental, perturbações emocionais severas ou perdas sensoriais (deficiências auditiva e/ou visual). 
A concepção de DA do presente estudo vem de estudos da Learning Disabilities Association of Canada (LDAC) ${ }^{5}$ e do National Joint Committee for Learning Disabilities (NJCLD) ${ }^{6}$, creditadas, por Hammill (1990), como consensuais: DA se refere a um grupo heterogêneo de desordens manifestadas por dificuldades significativas na aquisição e uso da audição, fala, leitura, escrita e da matemática. Tais desordens são intrínsecas, presumindo-se que sejam devidas a uma disfunção do sistema nervoso, que pode manifestar-se durante toda a vida. Problemas na autorregulação do comportamento, na atenção, na percepção e interação social podem coexistir com as DA. Convém ressaltar, entretanto, que, felizmente, uma única criança com DA não apresenta, ao mesmo tempo, todas as dificuldades inerentes às áreas acima citadas.

Encontrou-se grande diversidade nos parâmetros de seleção da amostra de escolares com DA, muito embora todos respeitem o consenso da NJCLD acerca da conjugação entre bom potencial cognitivo e baixo rendimento acadêmico, sendo considerados os já referidos fatores de exclusão. Foram encontrados na revisão teórica, em estudos do ano 2000 em diante, diferentes exemplos de parâmetros para seleção de amostras de estudantes com DA: opinião dos professores regentes, testes para exclusão de deficiência intelectual ${ }^{7}$, baixas médias escolares em dois bimestres consecutivos, com ou sem retenção no histórico escolar e posterior confirmação com testes de desempenho acadêmico, como TDE ${ }^{8}$ (STEIN, 1994), e alguns com aplicação de provas específicas, como a prova de aritmética para aferição de DA em cálculo (Assessment battery for children, de Kaufman e Kaufmann), propostos num estudo de Vilar (2010), e Escala de Identificação do Potencial de Aprendizagem em Fonseca e Oliveira (2009) (ALMEIDA, 2010; CAPELLINI; COPPEDE; VALLE, 2010; DIAS; ENUMO; AZEVEDO JUNIOR, 2004; FIN; BARRETO, 2010; MEDINA-PAPST; MARQUES, 2010; MOREIRA; FONSECA; DINIZ, 2000; PEREIRA, 2005; ROSA NETO et al., 2007; SILVA; BELTRAME, 2011).

A maioria delas apresenta esses parâmetros conjugados. A composição da amostra do presente estudo foi similar a essas pesquisas e será detalhada na metodologia.

Segundo a American Psychiatric Association (1995), na perturbação do cálculo, pode haver comprometimentos em várias competências: linguísticas - compreensão de termos aritméticos, decodificação de problemas em símbolos; perceptuais - reconhecimento dos símbolos e associação de objetos em grupos; de atenção - cópia correta, recordação de passos operacionais; e aritméticas - seguir algoritmos e contar objetos.

As DA em cálculo podem surgir associadas a um ou mais domínios da matemática, segundo Cruz (2003), que acrescenta a grande frequência de erros processuais e ansiedade tipicamente elevada na realização da tarefa.

\footnotetext{
${ }^{5}$ Disponível em: < http://www.ldac-acta.ca/>. Acesso em: 08 jul 2011.

${ }^{6}$ Disponível em: <http://www.ldonline.org/about/partners/njcld>. Acesso em: 08 jul 2011.

${ }^{7}$ Neste estudo, para exclusão de possível déficit intelectual, foi usado Matrizes de Raven - teste cognitivo que avalia habilidade não verbal no estabelecimento de relações analógicas para crianças de cinco a 11 anos. Mede habilidades específicas de raciocínio analítico - córtex pré-frontal e dorso-lateral (ANGELINI et al., 1999).

${ }^{8} \mathrm{TDE}$ - Teste de Desempenho Escolar - instrumento psicométrico brasileiro que avalia capacidades básicas do desempenho escolar nas áreas de escrita, aritmética e leitura (STEIN, 1994).
} 


\section{DA e expressão da motricidade}

Outro aspecto a destacar é que alguns autores apontam associação entre os problemas acadêmicos e desigualdade psicomotora (CORREIA, 2007). Estudos internacionais falam que $50 \%$ dos escolares com DA apresentam desordem no desenvolvimento da coordenação motora (GOEZ; ZELNIK, 2008; SMITS-ENGELSMAN et al., 2003).

Fonseca e Oliveira (2009) realizaram um estudo com escolares com e sem DA entre quatro e oito anos. O objetivo era identificar e comparar ambos os grupos acerca de aptidões: psicomotoras (construção de cubos, quebra-cabeças, sequências rítmicas, orientação direita/ esquerda, cópia de desenhos, desenho do corpo e formação de conceitos); motoras (coordenação de membros inferiores e superiores, e imitação); e índice geral cognitivo (aprendizagens verbais, numéricas e de memória). O resultado encontrado foi uma significativa correlação entre as aptidões psicomotoras e as de aprendizagem, e baixa correlação de ambas com as aptidões motoras. Para eles, as crianças sem DA são superiores em todas as variáveis de aptidão psicomotora em comparação com crianças com DA.

Por este motivo, uma fase preliminar deste estudo, transversal e descritiva, fez uma investigação, ao nível psicomotor, da mesma amostra - 37 sujeitos com indicativos de DA em cálculo - e encontrou uma correlação estatisticamente significativa entre noção espaço-temporal e DA em cálculo, resultado similar aos de outros estudos, na mesma temática, que encontraram relação entre déficts psicomotores e DA (ALMEIDA, 2007; ALMEIDA, 2010; FIN; BARRETO, 2010; FONSECA; OLIVEIRA, 2009; MEDINA-PAPST; MARQUES, 2010; PEREIRA, 2005; ROSA NETO et al., 2007; VILAR, 2010).

\section{Aprender matemática com o corpo}

A proficiência motora garantiria, segundo Moreira, Fonseca e Diniz (2000), a adaptabilidade ao maior número de situações com as quais os alunos se deparam ao escreverem, lerem e calcularem.

Um estudo experimental de Mourão-Carvalhal et al. (2007) descreve o sucesso de um programa pedagógico em geometria centrado no corpo/movimento realizado com escolares com baixas notas em geometria sujeitos a estímulo diferenciado do grupo controle.

Há uma crença antiga de que manipular objetos ou usar o próprio corpo como apoio para fazer matemática seria impedimento para uma necessária abstração (MUNIZ, 2007). Em contraposição, vale lembrar o conceito de abstração em Vergnaud (1996) e Piaget (1978) de que a mesma seria a internalização conceitual da ação concreta sobre o ambiente. Retomemos ao conceito atual da neurobiologia acerca da formação de imagens - mente, que cada sujeito experiencia de forma única e que dependerá, sobremaneira, das experiências vividas.

A dicotomização entre corpo e mente está no cerne do conceito de que aquele que mexe o corpo não desenvolve a mente (MUNIZ, 2007). Dicotomizar o pensar e o agir, segundo Muniz (2009), traz conceitos altamente pejorativos para o processo de aprendizagens acerca da racionalização de energia e de tempo, concentração e esforço - é mais inteligente quem faz mais rápido - e que gerou, a longo prazo, a eliminação total do corpo nas práticas pedagógicas escolares em geral. Tal crença produziu consequências sérias para a educação matemática. 
Muniz (2009) fala da necessidade do urgente resgate da integralidade do corpo-mente e acredita que a descoberta do potencial do corpo físico permitirá maiores conquistas da mente.

Há relatos de que a manipulação dos dedos seria uma das atividades mais privilegiadas para a construção do conceito de número (MUNIZ, 2007). A adoção de um sistema decimal por diferentes povos, em momentos históricos distintos, justifica a crença na importância da manipulação dos dez dedos; assim como foram, historicamente, o uso de partes do corpo para medir a terra: o passo, os pés, o palmo, o braço (jarda), o polegar (polegadas) e, do mesmo modo, a simetria do corpo humano para as noções de geometria (IFRAH, 1989).

Exercícios práticos/vivências lúdicas, como a justa divisão de uma quantidade qualquer, podem facilitar bases neuronais para a conceituação da divisão de quantidades contínuas (todo/parte), ou descontínuas, de forma satisfatória e formadora de sinapses que nenhuma explicação teórica poderia substituir. Magina e Campos (2004), num estudo com 248 crianças escolarizadas, baseado nos conceitos aditivos de Vergnaud (1996), também usados neste estudo (Quadro 1), relatam que, mediante um problema sobre medição de distâncias, a maioria delas movimentava seus dedos sobre o caminho, numa nítida reprodução dos passos físicos necessários para sua resolução.

Uma das principais justificativas para o uso do corpo/movimento enquanto metodologia advém da neurociência do aprendizado, levantada por Herculano-Houzel (2009): é mais fácil aprender com a colaboração do maior número possível de sentidos, ou seja, quanto mais recursos somatossensoriais forem empregados na transmissão de uma informação, melhor a qualidade das sinapses ocorridas para formação da memória de longa duração.

\section{Pressupostos do ensino da matemática e do uso do corpo/movimento - experiências somatossensoriais}

Os pressupostos de maior relevância neste âmbito considerados foram: Vergnaud (1996), com sua Teoria dos Campos Conceituais; Chevallard (1991), com o conceito fundamental de Transposição Didática, e Brousseau (1998, 2005), com a valorização das Situações Didáticas ou adidáticas.

Vergnaud (1996) propõe situações onde a soma e a subtração façam sentido prático para o aluno. Classificou os problemas aditivos em seis tipos (Quadro 1).

Em Chevallard (1991), é encontrada a afirmação de que não se trabalha na escola básica com a matemática pura. O produto do trabalho didático será sempre uma representação. A transposição didática poderá ser uma produção que contextualiza a representação que porta, onde devem estar implícitos seus valores social, cultural e educacional.

Brousseau (2005) busca compreender as relações que acontecem entre objeto do conhecimento, aluno-professor e o meio - situação didática. Brousseau (1998) conceitua situação "a-didática", porque, muitas vezes, o aluno apenas cumpre as regras de um contrato didático imposto. Neste sentido, o jogo pode suavizar o contrato didático e criar novos campos de experimentação livre e, portanto, de aprendizagem.

Para a construção da presente investigação centrada num programa pedagógico baseado no corpo/movimento, foram correlacionadas as contribuições destes três autores, com os já citados pressupostos das neurociências atuais da seguinte forma: (a) o programa foi focado na construção do ambiente pedagógico de modo a significar qualitativamente o conteúdo es- 
tudado, da forma mais adidática possível (BROUSSEAU, 2005), ao criar um espaço de maior liberdade psicológica, maior autonomia; (b) Tais alunos, considerados com DA, acabam por mobilizar, gerar e comunicar esquemas mentais (MUNIZ, 2009) e, assim, provocam a formação de sinapses duradouras (evocação das imagens formadas - "arquivo") a partir de experiências somatossensoriais significativas (DAMÁSIO, 1996; HERCULANO-HOUZEL, 2009); estas que, por sua vez, auxiliam a focar a atenção; (c) foi considerada, sobretudo, a significância do conteúdo estudado, cuidando para que a transposição didática não se distanciasse da aplicação ou do uso pragmático daquele conteúdo no cotidiano dos alunos (CHEVALLARD, 1991). Vergnaud (1996) foi importante para a escolha do tipo de situações-problemas matemáticas, adequando-as à faixa etária e buscando construir um modelo crescente de dificuldades.

Queremos salientar que usar os conceitos das neucociências na educação não se trata de criar uma espécie de treinamento cerebral fora do contexto escolar e, depois, transferir estes ganhos para a escola, os denominados neuromitos (RATO; CASTRO-CALDAS, 2010b). A respeito desta discussão, os autores afirmam que as últimas grandes contribuições das neurociências cognitivas, que podem e devem ser suas aplicações a influir nas teorias e práticas na educação, ainda não têm algo muito prático e aplicável. Fazem uma crítica, sobretudo, às tentativas de se criarem estas tais ginásticas cerebrais e similares, que se desconectam dos contextos onde estão inseridas as crianças ou escolares, e acabam por não auxiliar na construção de uma educação sólida.

Uma conexão interessante entre neurociências e educação é, justamente, seus pressupostos acerca de memória, afeto e atenção, que podemos usar a favor do aprendizado infantil, criando ambientes e situações facilitadoras, o que julgamos ter conseguido no presente estudo. Estudos recentes em neurociências relacionam a memória ao afeto e ao prazer do que está sendo ensinado. Para estudiosos da área, a memória é seletiva e altamente influenciada pela motivação e prazer (YZQUIERDO, 2010), motivo pelo qual as atividades eleitas nesta pesquisa foram baseadas em estratégias lúdicas de ensino da matemática, encontradas em vasta literatura, que, para além do prazer e motivação intrínsecos, permitem o uso do corpo/movimento de forma espontânea.

Por este motivo, o que ocorreu foi que, durante as investigações em neurociências do aprendizado/neurobiologia para a elaboração deste estudo, e com base em nossa experiência com educação de crianças há quase trinta anos, percebíamos que havia uma convergência entre as constatações atuais em estudos neurocientíficos e os estudos de educação matemática iniciados no Brasil, de forma mais explícita, nos anos 1980, por sua vez embasados em pesquisas da década de 1970 em diante. Citemos apenas alguns exemplos: as pesquisas sobre consciência e atividade, de Leontiev (1978), usando estímulos mentais/sensoriais significativos/associativos; de Moysés (1997), sobre compreensão superior em geometria, de alunos que fizeram manipulação de poliedros, comparativamente àqueles que não fizeram manipulação, sendo que, para estes últimos, a elaboração de conceitos complexos ocorreu antes mesmo de estes serem apresentados pelo professor; e pesquisas de Luria (1981) com memória e atenção.

Tais pesquisas estão pareadas com investigações similares atuais em neurociências, como, por exemplo, estudos com ressonância magnética (fMRI) que avaliaram o uso de palavras concretas e abstratas - manipuláveis e não manipuláveis, cujos resultados mostraram que objetos palpáveis são melhor e mais rapidamente lembrados devido ao envolvimento do maior número de sentidos, pois, além do verbal usado por ambos, o concreto aciona a representação imagética (visualização mental) adicional, mesmo depois da atividade realizada, ou seja, na ausência do objeto (WANG et al., 2010). 
$\mathrm{Na}$ verdade, o que tencionamos fazer neste estudo foi usar as contribuições teóricas das neurociências relativas à constatação da importância do uso do corpo e de experiências somatossensoriais e manipulativas, que geram motivação e atenção, e agregá-las aos estudos em educação matemática que já experienciam estes propósitos, muito embora de forma empírica; além das pertinentes discussões aqui apresentadas acerca das investigações neurocientíficas sobre cognição numérica, sobretudo os relevantes estudos de Dehane (1997, 2004), Kovas et al. (2007) e Núñez (2011).

\section{Metodologia}

Estudo longitudinal com 37 escolares com indicativos de DA em cálculo entre sete e 12 anos, de um colégio ${ }^{9}$ particular em Cuiabá, Mato Grosso, Brasil. Segue a Tabela 1, com perfil demográfico da amostra quanto a gênero e idade decimal.

Tabela 1. Distribuição da amostra total de acordo com o gênero e idade decimal

\begin{tabular}{lccc}
\hline & \multicolumn{3}{c}{ Idade } \\
\cline { 2 - 4 } & $\mathbf{N}$ & Média & Desvio padrão \\
\hline Masculino & $20(54 \%)$ & 8,83 & 1,30 \\
Feminino & $17(46 \%)$ & 8,77 & 1,34 \\
Total & $37(100 \%)$ & 8,80 & 1,29 \\
\hline
\end{tabular}

Fonte: elaborada pelos autores.

\section{Procedimento}

Após obtenção do parecer 555/2011 do Comitê de Ética em Pesquisa com Seres Humanos (CEP) da Escola de Saúde Pública do Estado de MT, e posterior assinatura do Termo de Consentimento Livre e Esclarecido (TCLE) pelos participantes, desenvolveu-se a pesquisa em quatro fases:

1. Seleção da amostra por meio de procedimentos adotados segundo estudos similares ${ }^{10}$ e em consonância com definição de DA do National Joint Committee on Learning Disabilities (NJCLD).

\footnotetext{
9 Trata-se de um grande colégio pertencente à rede salesiana, com cerca de quatro mil alunos na altura da investigação.

${ }^{10}$ Conjugação entre notas abaixo de 5 no pré-teste diagnóstico (teste padrão da unidade Cuiabá, proposto semestralmente para avaliação da performance dentro da rede salsesiana), e entrevista com professores regentes para confirmar os resultados dos testes e eleger alunos cuja média de desempenho acadêmico de, pelo menos, dois bimestres escolares consecutivos estivesse abaixo de 5. Para a seleção, foram respeitados os fatores de exclusão em DA, já citados - neste estudo, a exclusão de possível déficit intelectual foi feita pelo teste das Matrizes Progressivas Coloridas de Raven. (ANGELINI et al., 1999).
} 
2. Avaliação do desempenho psicomotor pela BPM ${ }^{11}$ (em ambiente isolado, sem influências externas e por dois pesquisadores) ${ }^{12}$;

3. Intervenção pedagógica centrada no corpo/movimento durante dois meses, em 24 sessões de 1h30; três vezes por semana; em grupos de até seis alunos por ano escolar (Quadro 1);

4. Duas avaliações - uma no término do programa (pós-teste 2) e outra três meses depois (pós-teste 1 - follow up) com o mesmo instrumento, para aferir os ganhos conservados.

\section{Intervenção pedagógica}

A área da matemática dos anos iniciais apresenta quatro domínios: números/operações; grandezas e medidas; espaço e forma (geometria); e tratamento da informação (estatística e probabilidade), expressos nos Parâmetros Curriculares Nacionais (PCN) (BRASIL, 2000), em concordância com as Normas Profissionais para o Ensino da Matemática (NATIONAL COUNCIL OF TEACHERS MATHEMATICS, 1994). Neste estudo, foi eleito o domínio dos números e operações.

Os objetivos do programa de intervenção pedagógica foram: (a) promover o desenvolvimento de habilidades do pensamento matemático e da resolução de problemas em alunos com indicativos de DA em cálculo; (b) promover o desenvolvimento de habilidades cognitivas em geral usando o corpo e vivências psicomotoras; (c) promover uma integração sensorial ao facilitar uma aprendizagem corporal - motora/psicomotora.

A escolha das atividades buscou favorecer um ambiente pedagógico que utilizasse informações somatossensoriais para melhor possibilitar a formação de imagens mentais duradouras, relacionando-as com os conteúdos eleitos a partir do teste diagnóstico, segundo relevância dos mesmos e maior dificuldade demonstrada pela amostra. Para tanto, foram usados materiais físicos, didáticos, manipulativos e favorecedores das experiências somatossensoriais: papel de gramatura boa para recorte, colagem e dobraduras, material emborrachado, plasticina (massa de modelar), varetas, caixas grandes e pequenas/embalagens vazias, objetos miniaturizados em madeira e plástico, jogo do troca-peça ${ }^{13}$, quadro de botões ${ }^{14}$, material dourado, tangram, jogos

\footnotetext{
${ }^{11}$ A Bateria Psicomotora (BPM) de Fonseca (1995) busca caracterizar os potenciais e dificuldades psicomotoras, ao avaliar: tonicidade, equilibração, lateralização, noção do corpo, estruturação espaço-temporal, praxia global e praxia fina. Neste estudo, foram avaliados somente os fatores sublinhados (que correspondem à $2^{\mathrm{a}}$ unidade funcional da BPM), por estarem mais relacionados às tarefas matemáticas. A estrutura espaço-temporal na qual encontrou-se correlação com DA em cálculo, avalia organização, estruturação dinâmica, representação topográfica e estruturação rítmicaI. Suas estruturações emergem da motricidade, da relação com os objetos localizados no espaço, da posição relativa que ocupa o corpo.

${ }^{12} \mathrm{Na}$ altura da aplicação da BPM, ambos os aplicadores eram acadêmicos do último semestre da Faculdade de Cuiabá (UNIC), orientados pela primeira autora deste estudo.

${ }^{13}$ Este jogo utiliza dados e peças coloridas que têm valor diferenciado e objetiva simular a lógica do agrupamento e troca da base decimal, porém em outras bases (neste caso, 5 e 3). Retirado de material instrucional denominado Mathema (SOARES; CASTRO; BURIASCO, 1989).

${ }^{14}$ Quadro de botões (ou sementes) é um material confeccionado em tecido ou material resistente, xadrez, em cujos quadrados, a intervalos regulares, se prendem dez (ou 12) botões, formando, no total, dez (ou 12) linhas e dez (ou 12) colunas. Permite a construção de conceitos e fixação de fatos básicos das quatro operações. É útil em frações, decimais, razões, proporções e porcentagem (CRUSIUS; GOMES; DANYLUC, [19--].
} 
de mesa, baralhos, dominós, réguas numéricas, material quadriculado em relevo, dinheiro chinês $^{15}$; consagrados na literatura especializada em Educação Matemática, tendo sido eleitos criteriosamente por permitirem desvelar conceitos que se pretendia evidenciar, respectivamente, para cada conteúdo de cada ano escolar.

Tais atividades envolveram metodologias ativas de aprendizagem. Além dos objetos físicos e as referidas situações de manipulação didática (a-didática), as atividades eleitas incluíram movimentos corporais, tanto de motricidade global quanto de pequenos movimentos, ou seja, de motricidade fina, que alguns teóricos denominam psicomotricidade, cuja distinção conceitual entre motricidade e psicomotricidade, eleita para este estudo, é dada por Fonseca (2004). O programa pedagógico constou das ações de classificar, juntar, separar, rolar, pular, montar, desmontar, agrupar, escolher, fazer, desfazer - por meio de: simbolização ou verbalização de ações, movimentos expressivos, orientação espacial, integração somatognósica, dissociação e planificação motora, elaboração de ideias, analogias, resolução de problemas, reversibilidade.

Exemplos de encaminhamento de sessões práticas:

- Será que todos os objetos rolam? Que tal experimentarmos rolar estes objetos aqui colocados (no centro da sala, havia objetos grandes, como: cubos, esferas (bolas), cilindros, pneus, arcos, cones, paralelepípedos e poliedros grandes de papel (pirâmides), caixas de sapato). Depois da experimentação, eram estimulados a dizer porquê alguns objetos não rolaram. "Porque têm cantos, porque não são arredondados", cujo conceito formal foi reelaborado a partir das suas argumentações. (sessão inicial do $2^{\circ}$. ano).

- Quantas viagens serão necessárias para levar seis baldes (dois a dois) até a mesa?

Quando Muniz (1999) fala que a ideia conceitual básica da matemática está embutida no material didático a ser explorado, quer dizer que, em tese, a manipulação do mesmo facilitará a evidência daquele pressuposto; e, ao manipulá-lo, o aluno acaba por se interessar em checar as regras de forma muito mais espontânea do que parece ocorrer nas aulas convencionais.

Os temas relativamente aos anos escolares estavam sempre relacionados a situações -problemas:

- $2^{\circ}$ Ano - Algoritmos escolares de adição/subtração;

- $3^{\circ}$ Ano - Algoritmos escolares de adição/subtração/multiplicação e divisão.

- $4^{\circ}$ Ano - Algoritmos envolvendo sistema monetário (lucros e perdas).

- $5^{\circ}$ Ano - Percentagem (fração de denominador decimal).

No início do programa, até aproximadamente a $9^{a}$ sessão, as atividades eram similares para todos os anos, priorizando o cálculo mental. Ao final, as sessões eram avaliadas pelos alunos e pela pesquisadora em ficha-protocolo específica.

\footnotetext{
${ }^{15}$ Dinheiro chinês: Carraher, Carraher e Schliemann (1988) e Carraher (1988) desenvolveram um sistema de dinheiro de brincadeira - dinheiro chinês - para vivência escolar. Proporciona três tópicos básicos do sistema decimal: (a) valores absoluto e relativo; (b) Relação entre essas propriedades e a escrita de números; (c) A relação entre o sistema decimal e a notação pelo valor posicional e os algoritmos escolares para resolução de operações aritméticas. Trata-se de fichas coloridas cujas diferentes cores representam valores diferenciados.
} 
Quadro 1. Encaminhamento das sessões práticas por conteúdo e respectivo ano escolar segundo os pressupostos matemáticos

\begin{tabular}{|c|c|c|}
\hline Ano escolar & Pressupostos Matemáticos & Atividades \\
\hline $2^{\circ}$ & $\begin{array}{l}\text { seis conceitos aditivos } \\
\text { de Vergnaud (1996): (1) } \\
\text { Transformação - mudança do } \\
\text { estado inicial que pode ser positiva } \\
\text { (Acrescentar +) ou negativa } \\
\text { (Tirar -); (2) Combinação de } \\
\text { medidas - junção predeterminada } \\
\text { de conjuntos de quantidades; (3) } \\
\text { Comparação - confronto de duas } \\
\text { quantidades para achar a diferença } \\
\text { (subtração); (4) Composição } \\
\text { de transformações - alterações } \\
\text { sucessivas do estado inicial; e (5) } \\
\text { estados relativos - transformação } \\
\text { de um estado relativo em outro } \\
\text { estado relativo; e (6) composição } \\
\text { de duas relações. }\end{array}$ & $\begin{array}{l}\text { - Cálculos digitais e mentais: "quantos } \\
\text { faltam para 10" - uso de réguas numéricas, } \\
\text { brincadeira "pega o monte" e jogos de } \\
\text { batalha de soma com baralho; } \\
\text { - Experimentação de rolagem de objetos } \\
\text { no chão (objetos grandes - cubos, esferas } \\
\text { (bolas), cilindros, pneus, arcos, cones, } \\
\text { paralelepípedos e poliedros de papel } \\
\text { (pirâmides), caixas de sapato; } \\
\text { - Classificação de figuras planas (tangrans } \\
\text { "gigantes" em papel pardo, do tamanho dos } \\
\text { participantes); } \\
\text { - Experimentação de possíveis soluções } \\
\text { de situações-problemas manipulando } \\
\text { as grandezas e decidindo a partir da } \\
\text { manipulação de objetos físicos ("Quantas } \\
\text { janelas abertas e fechadas possíveis em } 30 \\
\text { janelas"); }\end{array}$ \\
\hline
\end{tabular}

continua

\section{Resultados}

No Quadro 2 está o perfil da amostra por ano escolar. A Tabela 2 traz o resumo dos resultados das médias escolares antes e pós-programa. Ressalta-se, todavia, que o presente artigo pretende discutir os resultados qualitativos da proposta de intervenção pedagógica, ao demonstrar o tipo de atividades elencadas e respectivos pressupostos matemáticos (Quadro 1).

\section{Discussão}

Os ganhos significativos no desempenho matemático obtidos nos testes pós programas 1 e 2 indicam o impacto positivo de um programa de aritmética centrado no corpo/movimento no desempenho acadêmico de escolares com indicativos de DA em cálculo (Tabela 2).

Tal resultado assemelha-se aos resultados de Keller e Just (2009) acerca da melhora no desempenho acadêmico, cujo estudo mensurou, além dos testes acadêmicos convencionais similares aos do presente estudo, também, por meio da fMRI, o aumento da substância branca da janela semioval em crianças submetidas a programas de reforço escolar em leitura; bem como de estudos similares de intervenções pedagógicas citadas anteriormente, como a de MourãoCarvalhal et al. (2007). 
Quadro 1 . continuação

\begin{tabular}{|c|c|c|}
\hline Ano escolar & Pressupostos Matemáticos & Atividades \\
\hline $3^{\circ}$ & $\begin{array}{l}\text { Em Vergnaud (1996) e nos PCN } \\
\text { (BRASIL, 2000), o conceito } \\
\text { multiplicativo envolve: } \\
\text { proporcionalidade, configuração } \\
\text { retangular (área) e combinatória }{ }^{16}\end{array}$ & $\begin{array}{l}\text { - Cálculos digitais e mentais: "quantos } \\
\text { faltam para 10" -- uso de réguas numéricas, } \\
\text { brincadeira "pega o monte" e jogos de batalha } \\
\text { de soma com baralho; } \\
\text { - Distribuição de pernas-de-pau para crianças; } \\
\text { - Vestir (trocar) adereços em todas as } \\
\text { combinações possíveis; } \\
\text { - Distribuição de objetos em menor } \\
\text { quantidade de recipientes; } \\
\text { - Manipulação e confecção do quadro de } \\
\text { botões; } \\
\text { - Trabalho corporal em medições de área } \\
\text { com material sucata (quadrados de papel } \\
\text { pardo), rolar, caminhar, deitar, restringir até } \\
\text { áreas pequenas de mesas/carteiras usando } \\
\text { polígonos e sólidos planificados (anteriormente } \\
\text { tridimensionais); } \\
\text { - Brincadeira corporal: Jogo "O mapa da } \\
\text { minha área" (Mathema); } \\
\text { - Representação gráfica (desenhos ou ícones) } \\
\text { das decisões matemáticas; } \\
\text { - Organização de tabelas com objetos e } \\
\text { desenhos; } \\
\text { - Fatiar pães (massa de modelar) em um } \\
\text { número de fatias previamente determinadas; } \\
\text { - Brincadeira "Quem enche primeiro" } \\
\text { (BUCZEC, 2009, p. 52) - quantos copinhos } \\
\text { são necessários para encher um balde? } \\
\text { (recipientes de diferentes formatos e igual } \\
\text { capacidade). }\end{array}$ \\
\hline
\end{tabular}

continua

A aplicação do programa foi fundamental para aumento das notas, uma vez que as variáveis externas foram controladas - a amostra não recebeu orientações paralelas, como professores particulares ou outras intervenções extras.

Toda discussão oferecida pela neurociência do aprendizado foi confirmada: verificamos a função inegável da motivação, devido ao prazer do uso do corpo e a atenção focada, esta última conquistada, sobretudo, pela perpectiva da indissociabilidade do corpo-mente, quando

\footnotetext{
${ }^{16}$ Exemplo: quantas combinações diferentes posso fazer com cinco camisas e quatro blusas?
} 
Quadro 1 . continuação

\begin{tabular}{|c|c|c|}
\hline Ano escolar & Pressupostos Matemáticos & Atividades \\
\hline $4^{\circ}$ & $\begin{array}{l}\text { Sistema Monetário trabalha com três } \\
\text { diferentes aspectos simultaneamente: } \\
\text { propriedades básicas do sistema } \\
\text { decimal; relação entre essas } \\
\text { propriedades e a escrita numérica } \\
\text { pelo valor posição; e relação entre } \\
\text { ambos - propriedades e escrita - } \\
\text { e os algoritmos escolares para a } \\
\text { resolução de operações aritméticas. } \\
\text { A subtração (troco) envolve o } \\
\text { conceito de reagrupamento - trocar } \\
\text { notas de maior valor para pagar uma } \\
\text { determinada conta (CARRAHER; } \\
\text { CARRAHER; SCHLIEMANN, 1988). }\end{array}$ & $\begin{array}{l}\text { - Cálculos digitais e mentais: "quantos } \\
\text { faltam para 10" - uso de réguas numéricas, } \\
\text { brincadeira "pega o monte" e jogos de } \\
\text { batalha de soma com baralho; } \\
\text { - Uso do dinheiro chinês (CARRAHER, } \\
\text { 1988); } \\
\text { - Simulações de vendas (situações reais } \\
\text { com troco, compras, pagamentos); } \\
\text { - Jogo do troca-peça (bases } 10 \text { e 5); } \\
\text { - Pega-varetas gigante (BUCZEK, 2009, } \\
\text { p. } 70 \text { ). }\end{array}$ \\
\hline $5^{\circ}$ & $\begin{array}{l}\text { Percentagem }{ }^{17} \text { - relação com } \\
\text { conceito de fração de denominador } \\
100 . \text { O conceito implícito é de que, } \\
\text { para um efeito exclusivamente de } \\
\text { medida (parâmetro) social, costuma-se } \\
\text { comparar uma quantidade qualquer } \\
\text { com } 100 \text { (por cem). }\end{array}$ & $\begin{array}{l}\text { - Recortes de papel quadriculado - } 100 \\
\text { quadrados onde quantidades serão } \\
\text { distribuídas igualitariamente; } \\
\text { - Recorte do } 1 \% \text { - um quadrado dentre } \\
100 \text { quadrados (Vivenciando a relação de } \\
\text { proporcionalidade: um quadrado tem X } \\
\text { quantidade e Y quadrados terão...); } \\
\text { - Organização visual de } 50 \% \text { (metade), } \\
25 \% \text { (um quarto) em folhas de papéis } \\
\text { quadriculados (recortes); } \\
\text { - Distribuição de quantidades } \\
\text { descontínuas dentro deles (colocação de } \\
\text { azeitonas na pizza, bolinhas de massa de } \\
\text { modelar, riscos etc); } \\
\text { - Manipulação e confecção do quadro de } \\
\text { botões. }\end{array}$ \\
\hline
\end{tabular}

Fonte: Elaborado pelos autores.

das atividades manipulativas envolvidas. Para a neurociência do aprendizado, a atenção é fundamental ao ato de aprender, concluindo que não ocorre aprendizagem significativa quando a mesma não está focada (HERCULANO-HOUZEL, 2009).

Apropriar-se do conceito para literalmente tomá-lo nas mãos - é a metáfora que mais se aproxima do ocorrido no decorrer das sessões.

\footnotetext{
${ }^{17}$ Se tal quantidade fosse distribuída em cem quadrinhos, quantas ficariam em cada quadrinho?
} 
Quadro 2. Perfil da amostra por ano escolar

\begin{tabular}{|l|c|c|c|c|c|}
\hline & $\mathbf{2}^{\mathbf{o}}$ ano & $\mathbf{3}^{\mathbf{0}}$ ano & $\mathbf{4}^{\mathbf{o}}$ ano & $\mathbf{5}^{\mathbf{0}}$ ano & Total \\
\hline Número de alunos & 14 & 10 & 4 & 9 & 37 \\
\hline
\end{tabular}

Fonte: elaborada pelos autores.

Tabela 2. Média do desempenho no teste acadêmico matemático segundo gênero nos testes pré e pós programas 1 e 2

\begin{tabular}{lrccc}
\hline & N & Pré-teste & Pós-teste 1 & Pós-teste 1 \\
\hline Meninos (n=20) & $54 \%$ & 4,2 & 9,2 & 8 \\
Meninas (n=17) & $46 \%$ & 3,38 & 8,9 & 7,7 \\
Total (n=37) & $100 \%$ & 3,78 & 9,08 & 8,16 \\
\hline
\end{tabular}

Cotação: O teste de desempenho escolar tem escore de 0 a 10.

Fonte: elaborada pelos autores.

Comprovamos que situações manipulativas, de algum modo, aproximaram os participantes dos acertos esperados para os conceitos matemáticos envolvidos, e o grupo demonstrou relembrar muito mais daquilo que foi feito, do que foi apenas dito ou observado - este item refere-se ao aspecto somatossensorial - corpo/movimento da proposta (DAMÁSIO, 1996; HERCULANO-HOUZEL, 2009).

As repetições das atividades durante os dois meses do programa fizeram com que os acertos ficassem mais frequentes e disponibilizados para outras situações. Neste aspecto, também, a possível explicação é dada pela neurociênca do aprendizado: repetições fazem com que conteúdos guardados momentaneamente na memória de trabalho passem a fazer parte da memória de longa duração (HERCULANO-HOUZEL, 2009).

O resultado também pode ser mensurado qualitativamente por meio: das manifestações de alegria e adesão ao trabalho, melhora da autoestima, autossegurança e senso de autoeficácia, bem como aferido pelos resultados dos pós-testes 1 e 2 (Tabela 2).

Quanto mais direta era a relação do aluno com a situação proposta (exemplo da divisão de $\mathrm{n}$ baldes transportados dois a dois), mais fácil se tornava o entendimento do problema. Fato que não ocorria mediante somente leitura, mesmo que essa fosse feita pela professora. Evitou-se o trabalho exclusivamente via texto, para não prejudicar escolares que tivessem esta dificuldade associada. Por vezes, a decodificação do texto pode ser um obstáculo à matematização (MUNIZ, 2007).

\footnotetext{
${ }^{18}$ Segundo o INEP (2009), no Brasil, o desempenho acadêmico em matemática revela que não há diferença significativa entre meninos e meninas no Ensino Fundamental - dados similares foram encontrados no presente estudo.
} 
É suposto que haja uma intervenção/controle caso o mediador deseje conseguir certas aprendizagens usando jogos-situações. Houve, portanto, uma ação programada do professor mediatizando a atividade espontânea e a aprendizagem matemática.

A atividade matemática foi realizada na ação física sobre a estrutura lúdica da atividade. Observações do professor sobre a ação das crianças auxiliaram na percepção sobre o conhecimento de cada um e o potencial do aprendizado. O processo de argumentação do aluno sobre o feito matemático presente - ao justificar sua atitude mediante dada situação, por exemplo, metacognição, metacomunicação - possibilitou, muitas vezes, a tomada de consciência por eles próprios. Metacognição seria a materialização do "pensar como eu pensei”" e ocorre quando o sujeito que aprende, ao tentar explicar como fez ou justificar o porquê de sua tomada de decisão, se vê obrigado a pensar sobre seu conhecimento, tornando-se consciente da sua aprendizagem (MUNIZ, 2009).

Ainda, o professor como um dos participantes pôde facilitar a aprendizagem, ao estabelecer uma relação mais horizontal, com o cuidado de que suas decisões não fossem sempre acatadas, dada a hierarquia e poder representados pela sua figura.

Devido a subjetividade da proposta, queremos ressaltar que a reprodução deste estudo pode servir de orientação a futuras pesquisas, no entanto, cada momento - e cada mediador/ professor - tem seu modo de agir, suas ressignificações, de maneira tal que cada grupo de escolares será, inevitavelmente, singularmente diferenciado.

\section{Considerações finais}

Optamos por finalizar o texto citando António Nóvoa, que tem discutido com propriedade os rumos da escolarização atual, cuja experiência remonta como diretor de uma importante universidade portuguesa: "Na sociedade do conhecimento, a única maneira de incluir é conseguir que as crianças adquiram o conhecimento!” (NÓVOA, 2007, p. 8).

Assim, ao tomarmos emprestadas as palavras de Nóvoa (2007), reiteramos sua afirmação de que a educação atual em todo o mundo não consegue integrar os conhecimentos neurocientíficos às suas práticas. Ronda-lhe apenas o discurso...

Quanto a esta questão, retomemos Rato e Castro-Caldas (2010b), que creem que não devemos esperar milagres das pesquisas neurocientíficas aplicadas à educação, como, por exemplo, ginásticas cerebrais etc. - os neuromitos -, mas, sim, usar seus conceitos inovadores em prol de um ensino mais centrado no aprendizado, em estudar como ele ocorre efetivamente para as crianças, sobretudo, considerando o corpo e a mente dos escolares de forma mais integralizada. Infelizmente, a escola atual não tem conseguido incorporar, nas "pedagogias", tais estudos.

Lembremos, então, destas inovações, neste texto tratadas, e que devem ser levadas em consideração numa proposta pedagógica atual: funcionamento indissociável do organismo, ou seja, corpo-emoções - a química do estresse ou do medo prejudica ou, mesmo, impede o aprendizado; corpo-memória e corpo-consciência, que constituem, concordemos com Nóvoa (2007), questões extremamente instigantes e ainda longe das academias em todos os níveis de ensino. Recordemos, também, Yzquierdo (2010) e Damásio (1996), o segundo sobre liberação de serotonina e marcador somático. Ambos levantam questões a respeito da capacidade da me- 
mória humana, e o que pode acontecer a ela sob estresse - provas, outras pressões emocionais ou falta de desejo, agravadas em circunstâncias de DA.

Fonseca e Oliveira (2009) sugerem a persistência de déficits neuropsicológicos básicos em escolares com DA, e mostram que isto, além de requerer um trabalho pedagógico específico, também requer a identificação precoce destes perfis de escolares, constituindo-se o uso do corpo/movimento e aprendizagens motoras como novas ações pedagógicas possíveis para o sucesso escolar prospectivo de tais sujeitos.

\section{Referências}

ALMEIDA, E. Geometria através do corpo/movimento: impacto de uma proposta de intervenção transdisciplinar na aprendizagem da geometria no $1^{\circ}$ ciclo do ensino básico. 2007. 252 f. Dissertação (Mestrado em Ciências do Desporto) - Universidade de Trás-osMontes e Alto Douro, Vila Real, 2007.

ALMEIDA, R. N. S. Caracterizar o perfil psicomotor de crianças com dificuldades de aprendizagem com idades compreendidas entre 6 e 12 anos de idade. 2010. 105 f. Dissertação (Mestrado em Ciências do Desporto) - Universidade de Trás-os-Montes e Alto Douro, Vila Real, 2010.

AMERICAN PSYCHIATRIC ASSOCIATION. Manual de diagnóstico e estatística das perturbações mentais. 4. ed. Lisboa: Climepsi, 1995.

ANGELINI, A. L et al. Manual de matrizes progressivas coloridas de Raven: escala especial. São Paulo: Centro Editor de Testes de Pesquisas em Psicologia, 1999.

BRASIL. Ministério da Educação e Cultura. Secretaria de Educação Fundamental.

Parâmetros curriculares nacionais: matemática. Brasília, 2000.

BROUSSEAU, G. Introdução ao estudo das situações didáticas: conteúdos e métodos de ensino. São Paulo: Ática, 2005.

Théorie des situations didactiques. Grenoble: La Pensée Sauvage, 1998.

BUCZEK, M. R. M. Movimento, expressão e criatividade pela educação física: metodologia ensino fundamental $-1^{\circ}$ ao $5^{\circ}$ ano. Curitiba: Base Editorial, 2009.

CAPELLINI, S.; COPPEDE, A. C.; VALLE, T. R. Função motora fina de escolares com dislexia, distúrbio e dificuldades de aprendizagem. Pró-Fono Revista de Atualização Científica, São Paulo, v. 22, n. 3, p. 201-208, 2010. Disponível em: < http://www.scielo.br/ pdf/pfono/v22n3/a08v22n3.pdf >. Acesso em: 10 nov. 2011. 
CARRAHER, T. N. (Org.). Aprender pensando: contribuições da psicologia cognitiva para a educação. 3. ed. Petrópolis: Vozes, 1988.

CARRAHER, T. N.; CARRAHER, D. W.; SCHLIEMANN, A. D. Na vida dez, na escola zero: os contextos culturais da aprendizagem em matemática. In: Na vida dez, na escola, zero. 15. ed. São Paulo: Cortez, 1988. p. 23-43.

CHEVALLARD, Y. La transposition didactique: du savoir savant au savoir ensigné. Grenoble: La Pensée Sauvage, 1991.

CORREIA, L. M. Para uma definição portuguesa de dificuldades de aprendizagem específicas. Revista Brasileira de Educação Especial, Marília, v. 13, n. 2, p. 155-172, 2007. Disponível em: <http://dx.doi.org/10.1590/S1413-65382007000200002>. Acesso em: 10 nov. 2011.

CRUSIUS, M.; GOMES, C. H. P.; DANYLUK, O. Sistema de numeração e operações em diversas bases. Passo Fundo: Ed. da UPF, [19--].

CRUZ, V. Dificuldades na aprendizagem da matemática. Revista de Educação Especial e Reabilitação, Quebrada, v. 10, n. 2, p. 57-65. 2003.

DAMÁSIO, A. R. O erro de Descartes: emoção, razão e cérebro humano. São Paulo: Companhia das Letras, 1996.

DEHAENE, S. La bosse des maths. Paris: Odile Jacob, 1997.

DEHAENE, S. et al. Arithmetic and the brain. Current Opinion in Neurobiology, Oxford, v. 14, n. 2, p. 218-224, 2004.

DIAS, T. L.; ENUMO, S. R. F.; AZEVEDO JUNIOR, R. R. Influências de um programa de criatividade no desempenho cognitivo e acadêmico de alunos com dificuldade de aprendizagem. Psicologia em Estudo, Maringá, v. 9, n. 3, p. 429-437, 2004. Disponível em: <http://dx.doi.org/10.1590/S1413-73722004000300011>. Acesso em: 05 nov. 2010.

FIN, G.; BARRETO, D. B. M. Avaliação motora de crianças com indicadores de dificuldades no aprendizado escolar, no município de Fraiburgo, Santa Catarina. Unoesc\&Ciência ACBS, Joaçaba, v. 1, n. 1, p. 5-12, 2010. Disponível em: <http://editora.unoesc.edu.br/ index.php/acbs/article/view/47> Acesso em: 05 fev. 2012.

FONSECA, V. Manual de observação psicomotora: significação psiconeurológica dos fatores psicomotores. Porto Alegre: Artes Médicas, 1995.

Dificuldades de aprendizagem: abordagem neuropsicológica e psicopedagógica ao insucesso escolar. 3 ed. Lisboa: Âncora, 2004.

FONSECA, V.; OLIVEIRA, J. Aptidões psicomotoras de aprendizagem: estudo comparativo e correlativo com base na escala de Mccarthy. Lisboa: Âncora, 2009.

GOEZ H. R.; ZELNIK, N. Handedness in patients with developmental coordination disorder. Journal of Child Neurology, Thousand Oaks, v. 23, n. 2, p. 151-154, 2008. Disponível em: <http://jcn.sagepub.com/content/23/2/151.abstract>. Acesso em: 10 jan. 2011. 
Fernandes, C. T. et al.

HAMMILL, D. D. On defining learning disabilities: an emerging consensus. Journal of Learning Disabilities, Thousand Oaks, v. 23, n. 2, p. 74-85, 1990.

HERCULANO-HOUZEL, S. Neurociências na educação. Rio de Janeiro: CEDIC, 2009.

IFRAH, G. Os números: história de uma grande invenção. São Paulo: Global, 1989.

INEP. Matemática na educação básica. 2009. Disponível em: < http:/ / portal.inep.gov.br/ basica-levantamentos-microdados>. Acesso em: 25 maio 2011.

KAUFMANN, L.; DOWKER, A. Typical development of numerical cognition: behavioral and neurofunctional issues. Journal of Experimental Child Psychology, Maryland Heights, v. 103, n. 4, p. 395-399, 2009.

KELLER, T. A.; JUST, M.A. Altering cortical connectivity: remediation-induced changes in the white matter of poor readers. Neuron, Cambridge, v. 64, n. 5, p. 624-631, 2009. Disponível em: <http://www.ccbi.cmu.edu/reprints/Keller-Just_NEURON-2009_CCBIpreprint.pdf $>$ Acesso em: 10 jan. 2010.

KOVAS, Y. et al. Mathematical ability of 10-year-old boys and girls: genetic and environmental etiology of typical and low performance. Journal of Learning Disabilities, Thousand Oaks, v. 40, n. 6, p. 554-567, 2007. Disponível em: <http://www.ncbi.nlm.nih. gov/pmc/articles/PMC2967295/> Acesso em: 06 fev. 2015.

LEONTIEV, A. N. Actividad, conciencia y personalidad. Buenos Aires: Ciencias del Hombre, 1978.

LURIA, A. Fundamentos de neuropsicologia. São Paulo: Edusp: Livros Técnicos e Científicos, 1981.

MAGINA, S.; CAMPOS, T. M. M. As estratégias dos alunos na resolução de problemas aditivos: um estudo diagnóstico. Educação Matemática Pesquisa, São Paulo, v. 6, n. 1, p. 53-71, 2004.

MEDINA-PAPST, J.; MARQUES, I. Avaliação do desenvolvimento motor de crianças com dificuldades de aprendizagem. Revista Brasileira de Cineantropometria e Desempenho Humano, Florianópolis, v. 12, n. 1, p. 36-42, 2010.

MOREIRA, N. R; FONSECA, V.; DINIZ, A. Proficiência motora em crianças normais e com dificuldades de aprendizagem: estudo comparativo e correlacional com base no teste de proficiência motora de Bruininks-Oseretsky. Revista de Educação Física da UEM, Maringá, v.11, n. 1, p. 11-26, 2000.

MOURÃO-CARVALHAL, M. I. et al. A educação física e a matemática numa perspectiva de integração curricular. Vila Real: UTAD, 2007.

MOYSÉS, L. Aplicações de Vygotsky à educação matemática. Campinas: Papirus, 1997.

MUNIZ, C. A. Educação e linguagem matemática I. Brasília: UnB, 2007.

Jeux de société et activité mathématique chez 1'enfant.1999. 2 v. Thesis

(Doctoral - Sciences de l'éducation) - Université Paris Nord, Paris, 1999. 
- A produção de notações matemáticas e seu significado. In: FÁVERO, M. H.;

CUNHA, C. (Org.). Psicologia do conhecimento: o diálogo entre as ciências e a cidadania. Brasília: Unesco: UnB, 2009. v. 1, p. 115-143.

NATIONAL COUNCIL OF TEACHERS OF MATHEMATICS. Normas profissionais para o ensino da matemática. Tradução de E. Veloso. Lisboa: Associação de Professores de Matemática: Instituto de Inovação Educacional, 1994.

NÓVOA, A. Desafios do trabalho do professor no mundo contemporâneo: palestra. São Paulo: SINPRO-SP, 2007. Disponível em: <http://www.sinprosp.org.br/arquivos/ novoa/livreto_novoa.pdf>. Acesso em: 15 jan. 2013.

NÚÑEZ, R. E. No innate number line in the human brain. Journal of Cross-Cultural Psychology, Thousand Oaks, v. 42, n. 4, p. 651-668, 2011. Disponível em: < http://jcc. sagepub.com/content/42/4/651.abstract>. Acesso em: 25 jan. 2012.

PEREIRA, K. Perfil psicomotor: caracterização de escolares da primeira série do ensino fundamental de um colégio particular. 2005. 179 f. Dissertação (Mestrado em Fisioterapia) Universidade Federal de São Carlos, São Carlos, 2005.

PIAGET, J. Fazer e compreender. São Paulo: Melhoramentos, 1978.

Seis estudos de psicologia. 24. ed. Rio de Janeiro: Forense Universitária, 1999.

RATO, J. R.; CALDAS, A. C. Competências matemáticas emergentes: avaliação neuropsicológica de crianças em idade pré-escolar. In: SIMPÓSIO NACIONAL DE INVESTIGAÇÃO EM PSICOLOGIA, 7., 2010, Braga. Actas... Braga: Universidade do Minho, 2010a. p. 607-625. Disponível em: <http://ucp.academia.edu/JoanaRato>. Acesso em: 22 jan. 2011.

RATO, J. R.; CASTRO-CALDAS, A. Neurociências e educação: realidade ou ficção? In: SIMPÓSIO NACIONAL DE INVESTIGAÇÃO EM PSICOLOGIA, 7., 2010, Braga. Actas... Braga: Universidade do Minho, 2010b. p. 626-644. Disponível em: < http://ucp. academia.edu/JoanaRato>. Acesso em: 22 jan 2011.

ROSA NETO, F. et al. Desenvolvimento motor de crianças com indicadores de dificuldades na aprendizagem escolar. Revista Brasileira de Ciência e Movimento, Brasília, v. 15, n. 1, p. 45-51, 2007. Disponível em: <http://portalrevistas.ucb.br/index.php/RBCM/article/ viewFile/729/732>. Acesso em: 10 fev. 2015.

SILVA, J.; BELTRAME, T.S. Desempenho motor e dificuldades de aprendizagem em escolares com idades entre 7 e 10 anos. Motricidade, Vila Real, v. 7, n. 2, p. 57-68, 2011. Disponível em: <http://www.revistamotricidade.com/arquivo/2011_vol7_n2/v7n2a07. pdf> Acesso em: 21 jun. 2011.

SMITH, C.; STRICK, L. Dificuldades de aprendizagem de A a Z: um guia completo para pais e professores. Porto Alegre: Artmed, 2001. 
Fernandes, C. T. et al.

SMITS-ENGELSMAN, B. C. M. et al. Fine motor deficiencies in children with developmental coordination disorder and learning disabilities: an underlying open-loop control deficit. Human Movement Science, Amsterdam, v. 22, n. 4-5, p. 495-513, 2003. Disponível em: <http://dx.doi.org/10.1016/j.humov.2003.09.006>. Acesso em: 15 jan. 2010.

SOARES, E. S.; CASTRO, M. R.; BURIASCO, R. L. C. Mathema. Rio de Janeiro, 1989. (Não publicado).

STEIN, L. M. TDE - teste de desempenho escolar: manual para aplicação e interpretação. São Paulo: Casa do Psicólogo, 1994.

VERGNAUD, G. Estruturas aditivas e complexidade psicogenética. Porto Alegre: GEEMPA, 1996.

VILAR, C. E. C. Dificuldades de aprendizagem e psicomotricidade: estudo comparativo e correlativo das competências de aprendizagem académicas e de fatores psicomotores de alunos do $2^{\circ}$ e $4^{\circ}$ ano do ensino básico, com e sem dificuldades na aprendizagem. 2010. 69 f. Dissertação (Mestrado em Reabilitação Psicomotora) - Faculdade de Motricidade Humana, Universidade Técnica de Lisboa, Lisboa, 2010.

VIGOTSKY, L. S. A formação social da mente. 4. ed. São Paulo: Martins Fontes, 1991.

WANG, J. et al. Neural representation of abstract and concrete concepts: a meta-analysis of neuroimaging studies. Human Brain Mapping, Minneapolis, v. 31, n. 10, p. 1459-1468, 2010.

YZQUIERDO, I. A arte de esquecer: cérebro e memória. 2. ed. Rio de Janeiro: Vieira e Lent, 2010.

Artigo recebido em 19/05/13. Aceito em 16/07/14. 